\title{
Good servants, poor masters
}

\author{
Louis-Olivier Gagnon, MD; Martin E. Gleave, MD, FRCSC
}

The Vancouver Prostate Centre and Department of Urologic Sciences, University of British Columbia, Vancouver, BC

Cite as: Can Urol Assoc J 2014;8(5-6):163. http://dx.doi.org/10.5489/cuaj.2150 Published online June 16, 2014.

W e thank Dr. Valdivieso and Dr. Zorn for their commentary on our manuscript, ${ }^{1}$ but believe they overlooked the main point of the report. They state that robot-assisted laparoscopic radical prostatectomy (RALP) has emerged as the most popular approach in the US based on evidence indicating superiority over open radical prostatectomy (ORP). This is not true, and instead reflects widespread and sometimes disingenuous marketing by American institutions and manufacturers of the robot, coupled with the public's perception that any new technology is inherently better. The point of our report was to add to the growing position that a surgical tool is only as good as the operator. The surgeon, rather than the tool, is more important in optimizing outcomes. If you do an excellent ORP, the robot does not improve upon it; if you do not have excellent outcomes (and have, for example, transfusion rates above $10 \%$ ), then retraining with RALP may help improve outcomes. Our transfusion rates of $1.5 \%$ and hospital stay of 1.7 days using ORP are similar to RALP, and unlikely to be further reduced by RALP even beyond a learning curve of 200 cases.

This data are similar in a recent publication by Gandaglia and colleagues ${ }^{2}$ comparing outcomes of ORP and RALP in the Surveillance Epidemiology and End Results (SEER) database. Overall, 2439 patients (41.2\%) and 3476 patients $(58.8 \%)$ underwent ORP and RARP, respectively. Patients undergoing RALP had similar odds of overall complications, readmission, and additional cancer therapies compared with patients undergoing ORP. While RALP led to a lower risk of blood transfusion, it was associated with a higher probability of experiencing 30- and 90-day genitourinary and miscellaneous medical complications (all $p \leq 0.02$ ). As expected, costs were greater for patients undergoing RARP compared with ORP $(p<0.001)$. Another study published recently in CUAJ by Davison and colleagues ${ }^{3}$ shows comparable outcomes between ORP and RALP for health-related quality of life and regret.

Healthcare costs are growing at unsustainable rates, driven in part by the development of innovative technologies that tend to improve medical outcomes and increase cost. We need novel technologies that are either clearly superior, or at least non-inferior and less expensive. The bottom line is that RALP is not superior or cost-effective compared to ORP. If RALP is subjected to the same rigors of approval as new drugs are, by superiority or cost-benefit analyses, it would not meet the bar for approval based on the available evidence.

Competing interests: Dr. Gagnon declares no competing financial or personal interests. Dr. Gleave is a member of the Advisory Boards for Oncogenex, AstraZeneca, Janssen and Astellas. He is also a member of the Speakers bureau for Janseen and Astellas. He has consultantcy fees from Amgen, Janssen, Astellas and AstraZeneca. He holds a patent for a producted marketed by Oncogenex. He is also a founder and consultant for Oncogenex.

\section{References}

1. Valdivieso R, Zorn KC. Robot-assisted radical prostatectomy: Another Canadian experience. Can Urol Assoc J 2014;8:98-9. http://dx.doi.org/10.5489/cuai.2083

2. Gandaglia G, Sammon JD, Chang SL, et al. Comparative effectiveness of robot-assisted and open radical prostatectomy in the postdissemination era. J Clin Oncol 2014 Apr 14. [Epub ahead of print]

3. Davison BJ, Matthew A, Gardner AM. Prospective comparison of the impact of robotic-assisted laparoscopic radical prostatectomy versus open radical prostatectomy on health-related quality of life and decision regret. Can Urol Assoc J 2014;8:e68-72. http://dx.doi.org/10.5489/cuaj.480

Correspondence: Dr. Martin E Gleave, The Vancouver Prostate Centre and Department of Urologic Sciences, University of British Columbia, Level 6, 2775 Laurel Street, Vancouver, BC V6H 376; fax: 604-875-5654; m.gleave@ubc.ca 